Mistiaen, P., Poot, E., Hickox, S., Wagner, C. The evidence for nursing interventions in the Cochrane database of systematic reviews. Nurse Researcher: 2004, 12(2), 71-80

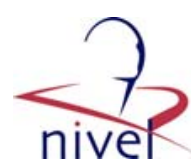

\begin{tabular}{|l|l|}
\hline $\begin{array}{l}\text { Postprint } \\
\text { Version } \\
\text { Journal website }\end{array}$ & 1.0 \\
Pubmed link & $\underline{\underline{\text { http://search.ebscohost.com/login.aspx?direct=true\&db=afh\&AN=15350793\&s }}}$ \\
\hline DOI & $\underline{\text { http://www.ncbi.nlm.nih.gov/pubmed/15636007 }}$ \\
\hline
\end{tabular}

This is a NIVEL certified Post Print, more info at http://www.nivel.eu

\title{
The evidence for nursing interventions in the Cochrane Database of Systematic Reviews
}

\author{
PATRIEK MistiaEN, ELSE ROOT, SOPHIE HickOX, AND CORDUla WAGNER
}

Patriek Mistiaen RN, MSN, Nurse Researcher, NIVEL, Netherlands Institute for Health Services Research, Utrecht, The Netherlands. Else Poot RN, MSN, Nurse Researcher, NIVEL, Utrecht, The Netherlands. Sophie Hickox RN, MS, Project Advisor, LEW, Utrecht, The Netherlands. Cordula Wagner PhD, Senior Researcher, NIVEL, Utrecht, The Netherlands,

In this paper, the autheurs describe how they conducted a search of the Cochrane Database of Systematic Reviews in order to explore the evidence for nursing interventions. They identify the number of studies, the number of participants, and the conclusions of systematic reviews concerning nursing interventions. They conclude that the Cochrane Database of Systematic Reviews is a valuable source of evidence about nursing interventions, and can be used as a means of developing a research agenda in the case of inconclusive review.

\section{INTRODUCTION}

One of the cornerstones of evidence-based practice is the systematic collection and analysis of all available research: the systematic review. Systematic reviews are important because they summarise the numerous and sometimes contradictory findings of primary research in a systematic way.

Systematic reviews may gather findings with regard to patient concerns, the prevalence of problems or diagnostic procedures. However, in recent years much attention has been paid to the effectiveness of healthcare interventions.

With regard to systematic reviews of healthcare interventions, the Cochrane Library (www.cochrane.org) is widely recognised as one of the most useful sources. The reviews carried out within the framework of the Cochrane Collaboration are highly valued because of their thorough searches and their methodological rigour (Alderson et al 2000). Although the Cochrane Library had its origins in medicine, many nursing textbooks and articles on evidence-based nursing also refer to the Cochrane Library (Craig et al 2002, Cullum 1997, Droogan et al 1998, Evans et al 1998, Stevens 2001). Therefore, we investigated the relevance ofthe Cochrane Database of Systematic Reviews (CDSR) for the nursing field. The following research questions were addressed:

- How many reviews in the CDSR are about nursing interventions?

- What kinds of nursing interventions have been the subject of a Cochrane review?

- How many studies and how many randomised control trials (RCTs) are usually included in these nursing reviews?

- How many participants are involved in these nursing reviews? 
- What are the final conclusions of these nursing reviews? We also wanted to investigate the relationship between the final conclusions of the review and the number of studies included, and the number of participants involved in the primary studies.

\section{METHOD}

The CDSR was searched on the CD-version of the Cochrane Library, 2002 issue 3 (ISSN 1464-780x), using a 'simple search' with the word 'nursing'.

In this way, all Cochrane reviews containing the word 'nursing' somewhere in the text, either as a keyword or as part of the title, abstract, text, authors or citations were identified. The title and abstract of all reviews produced by this search were then screened for relevance to the nursing field: the criterion that was applied to exclude or include a review was the definition of nursing according the International Council of Nurses: 'Nursing encompasses autonomous and collaborative care of individuals of all ages, families, groups and communities, sick or well and in all settings. Nursing includes the promotion of health, prevention of illness and the care of ill, disabled and dying people. Advocacy, promotion of a safe environment, research, participation in shaping health policy and in patient and healthsystems management, and education are also key nursing roles' (www.icn.ch).

For each review that was included we extracted data on the studied intervention, the study participants, the number of trials included, the number of RCTs included, the number of participants involved in the primary studies, and the conclusions ofthe review.

The interventions were classified into seven categories: psychological/ behavioural interventions (for example, cognitive rehabilitation, support, validation therapy), technical interventions (for example, beds, enemas, dressings), nutritional interventions (for example, dietary advice, zinc, fat supplementation), educational interventions (for example, providing information, patient education), exercises and positioning (for example, posture, muscle training), organisational interventions (for example, discharge planning, telemedicine), and mixed/other interventions. The conclusions were classified into four categories:

1. No studies found.

2. Insufficient evidence either to support or to refute.

3. Evidence that the intervention works positively.

4. Evidence that the intervention works negatively or has equal effect as the comparison intervention.

Categories 1 and 2 imply that these reviews are inconclusive, and that no evidence-based recommendations can be made with regard to the intervention: categories 3 and 4 imply that these reviews are conclusive or, in others words, that these reviews provide evidence that may guide practice.

Therefore, we categorised all reviews dichotomously into either 'conclusive' or 'inconclusive'.

Mainly descriptive statistics were used, and for the relationship between number of trials/participants and review conclusions, an independent Student's T-test was applied.

\section{RESULTS}

The CDSR of the Cochrane Library, 2002 issue 3 contained 1,456 complete reviews. The 'simple search' with the word 'nursing' resulted in 268 hits of complete reviews. Some ofthese reviews did indeed cover nursing issues and interventions, but while others contained the word 'nursing' somewhere, they clearly did not focus on any aspects of nursing.

By checking these references on their relevance for the nursing field, 160 reviews were retained and 108 excluded, because they obviously concerned specific medical topics, such as drugs or surgical techniques (a complete list ofthe included and excluded reviews can be obtained from the authors). 
Mistiaen, P., Poot, E., Hickox, S., Wagner, C. The evidence for nursing interventions in the

\section{Topics of the reviews}

A variety of nursing interventions have been the subject of a Cochrane systematic review. An overview ofthe interventions is presented in Table 1.

\section{[TABLE 1]}

Examples ofthese interventions included: • Psychological/behavioural interventions Reality orientation for dementia (Spector et al 2002), caregiver support for postpartum depression (Ray et al 2002), and cognitive rehabilitation for attention deficits following stroke (Lincoln etal 2002).

- Technical interventions Compression for venous leg ulcers (Cullum et al 2002b), absorbent products for the containment of urinary and/or faecal incontinence in adults (Shirran et al 2002), and hip protectors for preventing hip fractures in the elderly (Parker et al 2002).

- Nutritional interventions Dietary advice for illness-related malnutrition in adults (Baldwin etal 2002), nutritional supplementation for stable chronic obstructive pulmonary disease (Ferreira et al 2002) and cranberries for treating urinary tract infections (Jepson etal 2002).

- Educational interventions Education for contraceptive use by women after childbirth (Hiller eta/2002), interventions for educating children who have attended the emergency room for asthma (Haby et al 2002), and patient education for mechanical neck disorders (Cross et al 2002).

- Organisational interventions Commercial hospital discharge packs for breastfeeding women (Donnelly etal

- 2002), day hospital versus out-patient care for psychiatric disorders (Marshall etal 2002), and discharge planning from hospital to home (Parkes etal 2002).

- Exercises and positioning Exercise-based rehabilitation for coronary heart disease (Jolliffe etal 2002), kinesthetic stimulation for preventing apnoea in preterm infants (Henderson- Smart etal 2002), and pelvic floor muscle training for urinary incontinence in women (Hay-Smith etal 2002).

- Mixed/other interventions Smoking cessation in hospitalised patients (Rigotti etal 2002), optimal duration of exclusive breastfeeding (Kramer eta/ 2002), and speech and language therapy for aphasia following stroke (Greener et al 2002).

\section{Study populations}

There is a great diversity in the study populations that were targeted by the interventions. Study populations that were the focus of more than 10 reviews were babies and children, patients with cognitive impairment or psychiatric disorders, mothers/women, and patients with neurological disorders.

Between five and ten reviews were focused on older adults, patients with cardiovascular disorders, patients with pulmonary disorders, surgical patients, and smokers. Less than five reviews concerned patients with cancer, patients with hematological disorders, trauma patients, primary care patients and patients with renal diseases.

\section{Number of studies included}

Table 2 presents data on the number of studies included in a Cochrane nursing review and the sub-number of RCTs per review.

\section{[TABLE 2]}

It can be seen from Table 2 that there is a great variety in the number of included studies, varying from 0 to 52 . Half of the reviews included seven or less primary studies. It is notable that not all studies included in Cochrane reviews are RCTs, as is sometimes stated (Beaven 2002). 
Mistiaen, P., Poot, E., Hickox, S., Wagner, C. The evidence for nursing interventions in the Cochrane database of systematic reviews. Nurse Researcher: 2004, 12(2), 71-80

Table 3 shows the categorised number of studies included in a Cochrane nursing review.

\section{[TABLE 3]}

It can be seen from Table 3 that 8 per cent of the reviews included 0 studies and 33 per cent ofthe reviews included 1 to 5 studies: 35 per cent ofthe reviews included at least 10 primary studies.

\section{The number of participants involved}

The number of participants involved per review could be traced for 134 reviews (see Table 4).

\section{[TABLE 4]}

Most reviews (57 per cent) concerned a maximum of 100 participants.

However, there were very large numbers of participants involved in some of the reviews. Twelve reviews involved more than 10.000 participants, four of which concerned smokers, among whom it may be easy to conduct largescale primary studies.

\section{Conclusions of the reviews}

With regard to the conclusions ofthe reviews, there was 'no evidence due to no studies' found in 8.1 per cent: 'insufficient evidence either to support or to refute' in 51.9 per cent; 'evidence that the intervention works positively' in 32.5 per cent: and 'evidence that the intervention works negatively or has equal effect as the comparison intervention' in 7.5 per cent (Table 5). This means that 60 per cent ofthe reviews were inconclusive.

\section{[TABLE 5]}

\section{Relationship between the $f$ inai conclusions and the number of trials and the number of participants involved}

Reviews with a conclusive result included more studies than inconclusive reviews (mean 15.9 versus 6.3: Student's independent T-test, $\mathrm{p}=0.0001$ ).

Conclusive reviews also involved more participants than inconclusive reviews (mean 5,909 versus 1.14: Student's independent $T$-test, $\mathrm{p}=0.0001$ ): this is due not only to the fact that these reviews included more primary trials, but also because the primary trials in the conclusive reviews were generally on a larger scale (a mean number of 829 participants per trial in conclusive reviews versus 324 in the inconclusive reviews).

\section{DISCUSSION}

The Cochrane Database of Systematic Reviews contains over 150 complete reviews of interventions with relevance for the nursing field. A variety of nursing interventions in a diversity of study populations have been the subject of a Cochrane review.

The typical (median) Cochrane nursing review included 7 primary studies, 6 of which were RCTs. The median number of participants per review was 725 . This compares very well with the findings reported by AAallett et al for all reviews in the CDSR, Issue 1, 2001 (Mallett et al 2002). They found that a typical review included six trials, and a median of 945 participants per review. Earlier, Jadad eta/ (1998) found in the 1995 version ofthe CDSR that a typical Cochrane review included a median of five trials and of 528 participants.

This suggests that the nursing field does not differ very much from other healthcare fields with respect to the number of trials included in a Cochrane systematic review.

Systematic reviews based on more primary studies and larger study populations tended to report conclusive results more often than reviews that included a smaller number of trials and involved a smaller number of participants.

Forty percent of the reviews included in the analysis came to firm conclusions on important nursing issues, for example, concerning beds, mattresses and cushions for pressure sore 
Mistiaen, P., Poot, E., Hickox, S., Wagner, C. The evidence for nursing interventions in the Cochrane database of systematic reviews. Nurse Researcher: 2004, 12(2), 71-80

prevention and treatment (Cullum et al 2002a) or interventions for preventing falls in elderly people (Gillespie et al 2002).

On the other hand, more than half ofthe reviews included in the analysis concluded that there was insufficient evidence, and another 8 per cent could not even include any trials. This means that for 60 per cent of the nursing topics studied in a Cochrane review there is no evidence to guide practice.

However, these inconclusive reviews may help to reduce uncertainty, and they may also provide a valuable source of information to identify areas in which research is needed.

In summary, the CDSR is a valuable source of information about the stateof- the-art with regard to the effectiveness of many nursing interventions.

When conclusive reviews are available, the CDSR can be used as a basis for the development of clinical guidelines or as an aid in clinical decision making: inconclusive reviews in the CDSR can provide useful information that can be used to develop a research agenda.

This article has been subjected to a double-blind review

Alderson P etai (2000) Should journals publish systematic reviews that find no evidence to guide practice? Examples from injury research. British Medicai Journai. 320, 7231,375377.

Baldwin C etai (2002) Dietary advice for illness-related malnutrition in adults. Cochrane Library Database Systematic Review. Issue 3, Oxford Update Software.

Beaven 0 (2002) Searching the literature. In: Craig JV, Smyth RL (Eds) The Evidence-Based Practice Manual for Nurses. London, Churchill Livingstone.

Cullum N (1997) Identification and analysis of randomised controlled trials in nursing: a preliminary study. Quaiity in Health Care. 6, 1, 2-6.

Cullum N etai (2002a) Beds, mattresses and cushions for pressure sore prevention and treatment. Cochrane Library Database Systematic Review. Issue 3, Oxford Update Software.

Cullum N ef ai (2002b) Compression for venous leg ulcers. Cochrane Library Database Sptematic Review. Issue 3, Oxford Update Software.

Donnelly A et ai (2002) Commercial hospital discharge packs for breastfeeding women. Cochrane Library Database Systematic Review. Issue 3, Oxford Update Software.

Droogan J ef ai (1998) Systematic reviews in nursing, internationai Journai of Nursing Studies. 35, 1-2, 13-22.

Evans D ef a/(1998) Systematic reviews in nursing research. Austraiian Nursing Journal. 5, 10, 42-42.

Ferreira IM etai (2002) Nutritional supplementation for stable chronic obstructive pulmonary disease. Cochrane Library Database Systematic Review. Issue 3, Oxford Update Software.

Gillespie LD et al (2002) Interventions for preventing falls in elderly people. Cochrane Library Database Systematic Review. Issue 3, Oxford Update Software.

Greener J ef ai (2002) Speech and language therapy for aphasia following stroke. Cochrane Library Database Systematic Review. Issue 3, Oxford Update Software.

Gross AR etai (2002) Patient education for mechanical neck disorders. Cochrane Library Database Systematic Review. Issue 3, Oxford Update Software.

Haby MM ef ai (2002) Interventions for educating children who have attended the emergency room for asthma. Cochrane Library Database Sptematic Review. Issue 3, Oxford Update Software.

Hay-Smith EJ etal (2002) Pelvic floor muscle training for urinary incontinence in women. Cochrane Library Database Systematic Review. Issue 3, Oxford Update Software.

Henderson-Smart DJ ef ai (2002) Kinesthetic stimulation for preventing apnea in preterm infants. Cochrane Library Database Systematic Review. Issue 3, Oxford Update Software.

Hiller JE ef a/ (2002) Education for contraceptive use by women after childbirth. Cochrane Library Database Systematic Review. Issue 3, Oxford Update Software. 
Mistiaen, P., Poot, E., Hickox, S., Wagner, C. The evidence for nursing interventions in the Cochrane database of systematic reviews. Nurse Researcher: 2004, 12(2), 71-80

Jadad AR ef ai (1998) Methodology and reports of systematic reviews and meta-analyses: a comparison of Cochrane reviews with articles published in paper-based journals. Journal of the American Medical Association. 280, 3, 278-280.

Jepson RG ef al (2002) Cranberries for treating urinary tract infections. Cochrane Library Database Systematic Review. Issue 3, Oxford Update Software.

Jolliffe JA ef al (2002) Exercise-based rehabilitation for coronary heart disease. Cochrane Library Database Systematic Review. Issue 3, Oxford Update Software.

Kramer MS ef a/ (2002) Optimal duration of exclusive breastfeeding. Cochrane Library Database Systematic Review. Issue 3, Oxford Update Software.

Lincoln NB ef ai (2002) Cognitive rehabilitation for attention deficits following stroke. Cochrane Library Database Systematic Review. Issue 3, Oxford Update Software.

Mallett S ef al (2002) The typical Cochrane review: How many trials? How many participants? International Journal of Technology Assessment in Healthcare. 18,4,820-823.

Marshall M ef al (2002) Day hospital versus outpatient care for psychiatric disorders. Cochrane Library Database Systematic Review. Issue 3, Oxford Update Software.

Parker MJ etal (2002) Hip protectors for preventing hip fractures in the elderly Cochrane Library Database Systematic Review. Issue 3, Oxford Update Software.

Parkes J etal (2002) Discharge planning from hospital to home. Cochrane Library Database Systematic Review. Issue 3, Oxford Update Software.

Ray K I etai(2002) Caregiver support for postpartum depression. Cochrane Library Database Systematic Review. Issue 3, Oxford Update Software.

Rigotti NA ef ai (2002) Interventions for smoking cessation in hospitalised patients. Cochrane Library Database Systematic Review. Issue 3, Oxford Update Software.

Shirran E ef ai (2002) Absorbent products for the containment of urinary and/or faecal incontinence in adults. Cochrane Library Database Systematic Review. Issue 3, Oxford Update Software.

Spector A ef al (2002) Reality orientation for dementia. Cochrane Library Database Systematic Review. Issue 3, Oxford Update Software.

Stevens KR (2001) Systematic reviews; the heart of evidence-based practice. AACN. Clinical Issues. 12,4,529-538.

\section{TABLES}

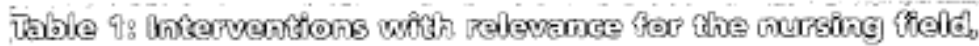
Etudied )

$\begin{array}{lcc}\text { Type of intervention } & \text { Frequency } & \text { Percentage } \\ \text { Psychologicalbehavioural interventions } & 28 & 17.5 \\ \text { Technical interventions } & 28 & 17.5 \\ \text { Nutritional interventions } & 14 & 8.8 \\ \text { Educational interventions } & 19 & 11.9 \\ \text { Organisational interventions } & 29 & 18.1 \\ \text { Exercises \& positioning interventions } & 18 & 11.3 \\ \text { Mixed/other interventions } & 24 & 15.0\end{array}$


Mistiaen, P., Poot, E., Hickox, S., Wagner, C. The evidence for nursing interventions in the Cochrane database of systematic reviews. Nurse Researcher: 2004, 12(2), 71-80

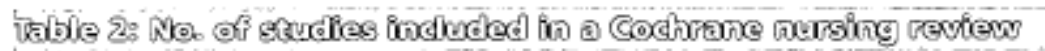

$\begin{array}{lcc}\text { Statistic } & \begin{array}{c}\text { Number of studies included } \\ (\mathbb{N}=159 \text { valid/1 missing) }\end{array} & \begin{array}{c}\text { Number of } \mathrm{RCT} \text { included } \\ (\mathrm{N}=153 \text { valid } / 7 \text { missing) }\end{array} \\ \text { Mean } & 10.19 & 8.84 \\ \text { Median } & 7 & 6 \\ \text { Mode } & 3 & 2 \\ \text { Standard deviation } & 10.36 & 9.91 \\ \text { Minimum } & 0 & 0 \\ \text { Maximum } & 52 & 52\end{array}$

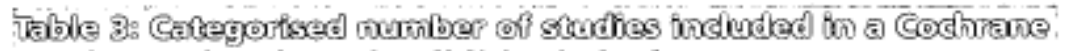

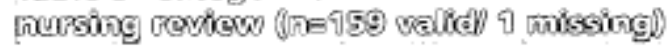

$\begin{array}{lccc}\text { no studies } & \text { Frequency } & \begin{array}{c}\text { Valid } \\ \text { percentage }\end{array} & \begin{array}{c}\text { Cumulative } \\ \text { percentag }\end{array} \\ 1-5 \text { studies } & 13 & 8.2 & 8.2 \\ 6-10 \text { studies } & 53 & 33.3 & 41.5 \\ 11-15 \text { studies } & 38 & 23.9 & 65.4 \\ 16-20 \text { studies } & 20 & 12.6 & 78.0 \\ 21 \text { or more studies } & 11 & 6.9 & 84.9 \\ & 24 & 15.1 & 100.0\end{array}$

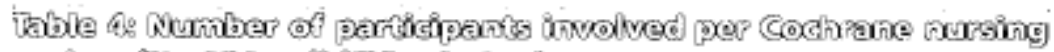

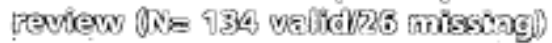

$\begin{array}{lr}\text { Mean } & 3,211 \\ \text { Median } & 725 \\ \text { Standard deviation } & 7,206 \\ \text { Minimum } & 12 \\ \text { Maximum } & 56,990\end{array}$

Most reviews (57 per cent) concerned a maximum of 100 participants. However, there were very large numbers of participants involved in some of the reviews. Twelve reviews involved more than 10.000 participants, four of which concerned smokers, among whom it may be easy to conduct largescale primary studies.

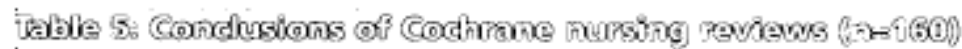

\begin{tabular}{llll} 
Conclusion & Frequency & \multicolumn{1}{c}{$\begin{array}{c}\text { Valid } \\
\text { percentage }\end{array}$} & $\begin{array}{c}\text { Cumulative } \\
\text { percentage }\end{array}$ \\
no studies found & 13 & 8.1 & 8.1 \\
insufficient evidence & 83 & 51.9 & 60.0 \\
positive evidence & 52 & 32.5 & 92.5 \\
negative or equal evidence & 12 & 7.5 & 100.0
\end{tabular}

